\title{
The Matrix of Needs: Reframing Maslow's Hierarchy
}

\author{
Bob Bowen \\ Positive Behaviour Support, Prag Consulting, Melbourne, Australia \\ Email: bob@matrixofneeds.com
}

How to cite this paper: Bowen, B. (2021) The Matrix of Needs: Reframing Maslow's Hierarchy. Health, 13, 538-563.

https://doi.org/10.4236/health.2021.135041

Received: April 7, 2021

Accepted: May 18, 2021

Published: May 21, 2021

Copyright (c) 2021 by author(s) and Scientific Research Publishing Inc. This work is licensed under the Creative Commons Attribution-NonCommercial International License (CC BY-NC 4.0). http://creativecommons.org/licenses/by-nc/4.0/

\begin{abstract}
In his original article on human motivation, Abraham Maslow said "The present theory then must be considered to be a suggested program or framework for future research and must stand or fall, not so much on facts available or evidence presented, as upon researches yet to be done, researches suggested perhaps, by the questions raised in this paper" ([1], p370). This article endeavours to build on Maslow's work, incorporating research in the neurobiological impact of childhood trauma which shows that safety is the most fundamental need for all human beings. Indigenous approaches to understanding human needs beyond the ending points of any one individual life and valuing cultural perpetuity are also integrated into this model. The methodology to synthesize this paper is the result of a transdisciplinary approach which values collaboration between disciplines that focus on the biological, social, and psychological factors that interact with each other in the dynamic dance of life. Communication is added as a core need of human beings, with Interdependent Actualization being seen as the capstone of human development. Incorporating the biological framework of the extra-cellular matrix with a visual model that shows the relationships between the parts of a whole, the Matrix of Needs restores the dynamic and interrelated nature of human needs in the same hope Maslow had, that this paper will generate ideas, launch discussions and build a framework for future researchers to better understand what it means to be human, and how to remove the barriers which impede our growth as individuals and as members of the human family.
\end{abstract}

\section{Keywords}

Human Needs, Interdependent, Trauma, Wellness, Communication, Attachment

\section{Introduction}

Maslow's Hierarchy of Needs [1] is one of the most recognizable psychological 
concepts in the world. There have been efforts to renovate the model [2], replace the model [3], update the model with some of Maslow's later writings [4] or expand the model [5]. Despite these efforts, Maslow's approach to understanding human needs continues to be widely used in business, education, and human service settings.

This article endeavours to build on Maslow's work, incorporating research in the neurobiological impact of childhood trauma [6] and the impact of unsafe conditions on the process of meeting needs which shows that safety is the most fundamental need for all human beings [7]. Since the publication of Maslow's paper and thousands of subsequent articles, books, and presentations, the concept has lost its dynamic inter-relatedness and become what Maslow was afraid it would become, a list of needs that are often seen as progressive but not interrelated. The Matrix of Needs restores the dynamic and interrelated framework of human needs in a new format which is written in the same hope Maslow had, that this paper will generate ideas, launch discussions and build a starting point for future researchers to better understand what it means to be human, and how to remove the barriers which impede our growth as individuals and as members of the human family.

The process of becoming human cannot be captured by a list of needs to be addressed, met, and then relegated to some kind of maintenance mode. Rather, it is a life-long process of assimilation, disequilibrium, and accommodation, a theory developed by Jean Piaget and adapted into Cognitive Development Theory [8]. As we go through our day-to-day lives, novel experiences produce a sense of disequilibrium, in which we compare what we are experiencing to our past experiences. It is in this stressful process that we can experience growth if we decide to accommodate the new information, the new experience, the new sensation into our psychological and emotional frameworks. This life long process requires a flexible model that can adapt to the continual stresses of growth and adaptation, and it requires a sense of safety in order for equilibrium to be reestablished.

In cellular biology, there is a concept known as the "extracellular matrix", or ECM, that provides the form within which the function of the cells are able to be expressed in ways that sustain the life of that particular organism [9] [10]. Human beings have ECM's throughout their bodies, and because of the unique properties and needs of different cells, there are multiple ECM structures within all complex organisms. In a very real sense, the ECM is the glue that holds us together [11].

From a psychological perspective, safety is the glue, the matrix, that holds our psychological selves together, even at the basic levels of subsistence needs such as eating and sleeping. When we experience trauma, one of the descriptors of the effect of trauma is that it "messes with the housekeeping issues of the body" [12]. The ECM, which will be referred as the Matrix of Needs from this point forward, has as its' underpinning an understanding of and belief in the importance of 
safety for all human endeavours and actions. In addition, the biological conceptualization of the Matrix of Needs, a matrix is also a model that facilitates the presentation of interrelated data in a visual format. The visual model used to present this model relies on specific placements of needs to present their interrelatedness with each other.

As we go through our lives and interact with our environments and the beings in them, growth can only occur if we feel safe enough to risk failure, especially at a psychological and emotional level. If we do not feel safe during the process of experiencing and learning, then our efforts to learn and to participate will be partially or fully futile [13]. The importance of safety to the process of becoming human cannot be overstated and must be at the center of our efforts at supporting people throughout life [14].

For human beings, safety is found, in the words of the old adage, in numbers. The Social Engagement System has been hypothesized to have evolved to empower humans and other primates to develop the social skills necessary for group as opposed to individual actions [15]. Humans are relatively weak animals in isolation; it is only through social interaction that humans were able to overcome predators and harsh environmental conditions necessary for survival [16]. Safety is the result of our social relationships, and it is our ability as humans to work interdependently that empowered us to be able to adapt to almost every environment on earth. Rather than a question of human behaviour being shaped by nature or nurture, safety through interdependence is a "both-and" and not an "either-or" appreciation of how social interactions impacted human evolution over time.

The concept of epigenetics reinforces this "both-and" idea. Epigenetics, broadly speaking, states that the experiences of individuals are incorporated into their genetic code throughout the lifespan. As our individual cells are replaced in our bodies, environmental experiences are encoded through what are known as methyl groups that do not change the base pair of the chromosome but do change genetic expression by switching instructions coded within our DNA on or off [17] [18]. Thousands of generations of humans passed on and added to the relational nature of being human into our overall genetic structure. As a species as well as individuals, social behaviours are necessary for survival, and this is why there are different levels of relationships in the process of becoming human.

At a neurological level, human beings are designed to live in social groupings and interact with each other on an almost continual basis [19]. When we are forced to limit our social interactions, as is the case of the COVID-19 Pandemic of 2020 and 2021, the threats to our social safety have an impact on the entire person, and one could argue, on the entire society. The Matrix of Needs attempts to identify needs through the observation of human behaviour, with a primary focus on people with complex trauma histories. It is easier to identify needs when they are unmet, when people struggle under the weight of their pain. The 
processes involved in becoming human are seen in stark relief in the pain of the lives of the people I serve, and have served, in the United States, Canada, Europe, and Australia. It is also seen in the resilient joy of healing when needs are finally and fully met in their lives.

\section{An Overview of the Matrix of Human Needs}

The Matrix of Needs is organized into 5 different processes. The word "processes" is used to clarify that the needs are ongoing, inter-related and dynamic. As a man considered to be a "senior citizen" I am still reliant on all the processes involved in becoming and being human. The developmental tasks differ at different ages, but are always present in my life, the lives of hundreds of others I have talked to about this, and thousands of others with whom I have interacted (Figure 1).

\subsection{Safety}

Safety-emotional, physical, psychological, social, sexual-has already been identified as a continuous need throughout the lifespan. As such, it is not a process need but a structural need. When people feel safe at all these different levels they become less aware of the need for safety until safety is absent.

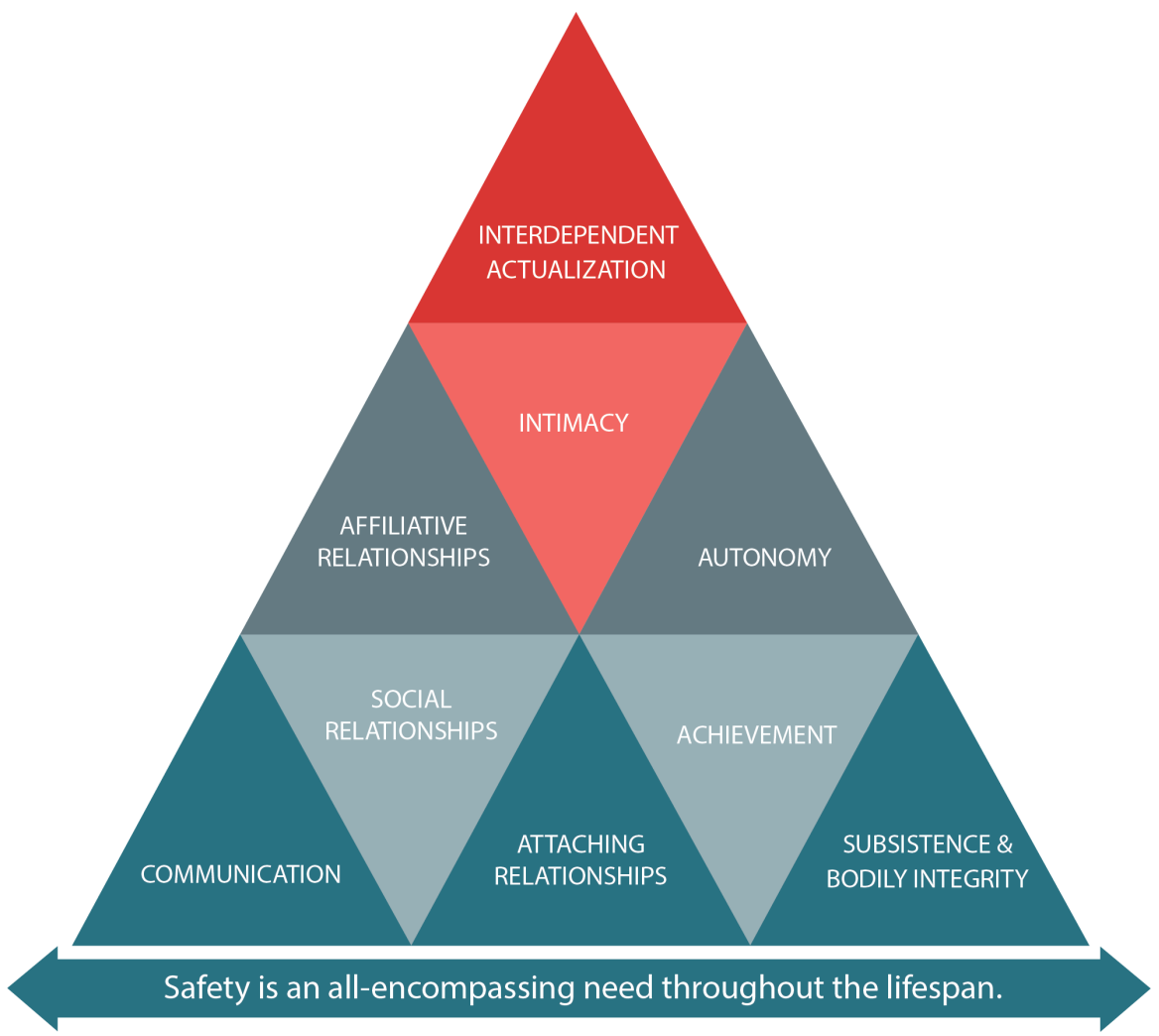

Figure 1. A visual representation of the component dynamic processes which interact with each other in the journey to become human. Safety is more than a component need, it is a comprehensive need at all times throughout life and as such is represented by the double-arrow at the base of the model. 


\subsection{Core Needs: Subsistence, Attaching Relationships, Communication}

These needs form the core for human life. Our subsistence needs-food, water, shelter, excretion, and sleep-are required for us to survive. Without them, we would die within minutes, days or weeks depending on which one, or ones of these components of subsistence we are missing. Without stable Attaching Relationships, human beings have difficulty in social relationships throughout their lifespan, based on research in attachment theory discussed later in the paper. Communication is, for many people, a novel concept as a foundational need. However, without communication social relationships could not exist. We need to be able to communicate in order to survive.

\subsection{Growth Needs: Achievement, Social Relationships}

Once our foundational processes are in place, we then can work on the next set of processes, which are Achievement and Social Relationships. Those of us who have had the experience of raising or being around small children have heard the "I do it" pride of a child practicing their independence in some kind of skill. At the same time, they are working on achieving a goal, they are also working on developing their social relationships beyond the base attachments formed with significant adults in their lives.

\subsection{Maturity Needs: Autonomy and Affiliation}

As we mature, our next needs are for a combination of Autonomy and Affiliative Relationships. Moving from the "I do it" process we now begin to map out our independence from our families of origin and individuate, distinguishing ourselves as individuals in our own right. Relationships now become a matter of choice as we identify others with whom we want to belong, whether it is a group at work, or an expression of faith, or an expression of creation such as music, or physical activities such as mountain climbing, etc. These are people groups we choose to identify with as opposed to being born or placed into them.

\subsection{Fulfillment Need: Intimacy}

Intimacy is the ability to be honest with one or more people with no fear of rejection. It is far more than physical intimacy, although for many people that is the first concept we associate with the word intimacy. Brene Brown's work on vulnerability provides a good frame for understanding intimacy [20] and our need to have deep relationships where we can say anything with no fear that we will be rejected. In some ways, this represents self-actualization, for we have 'arrived" at what it means to be human at an individual level.

\subsection{Interdependent Actualization}

To actualize something means: "to make something that could possibly happen or be achieved really happen or be achieved" [21]. In the Matrix of Needs model, 
the self is actualized, fully achieved, through the processes culminating in Affiliative Relationships, Autonomy, and Intimacy. Our next need, both as individuals, communities and indeed as a species, is Interdependent Actualization.

Interdependency, the concept that we are all in this together, provides a way of understanding human actions and interactions in a way that is consistent with the Social Engagement System which postulates that human social behaviour in response to threats has evolved to empower humans to work in groups as opposed to addressing threats individually [22]. Interdependency balances the needs of the self and the needs of the group. There is in western social thought an individualism or collectivism approach, which provides a false dichotomy. We are born as individuals and become human through social interactions.

The current boundaries of assessing successful actualization are the birth and death of individuals. Indigenous models, however, take a longer view of the impact of our actions and/or inactions. The " $7^{\text {th }}$ generation principle" of the Haudenosaunee, or the Iroquois Confederacy, states that the decisions made today should take into account the people living seven generations from now [23]. Interdependency is not just within the here and now of life, it is within the broader scope of who we are as a people, a species, in both space and time.

\section{Safety Is More Than a Separate Need}

When safety is not present, people use behaviour in order to procure safety for themselves and others [24] [25]. Safety is represented by the double-sided arrow beneath the pyramidal structure in Figure 1. Human beings monitor their environments to determine how safe they are through the sympathetic and parasympathetic nervous systems [26]. These threat and safety assessments are focused on psychological and social forms of safety, not just physical. As such, safety cannot be a unique need separated from other needs; rather, it is a continuous need present in all human interactions.

At the same time safety is or is not being established for the person, their first needs are for subsistence, attachment, and communication. Many readers will agree with the concepts of subsistence and attachment being primary needs that must be met first, and the addition of communication as a need may seem out of place. It will be shown later in this article that communication is necessary for all human activities, and that the evolutionary groundwork for communication was developed far earlier than originally thought, dating back approximately 25 million years [27].

When these needs are met in conditions of safety, the child will have laid down a foundation for future growth that is absolutely essential. When safety is not present, through abuse and neglect, even though food may be offered, the developmental trajectory of the child is altered in significant ways [28]. Safety and human interactions are woven together at a neurological level [29] [30]. The brains of infants are able to process somatosensory input in the amygdala and are hypersensitive to threat [31]. The presence of responsive adults in the envi- 
ronment mitigates the fear associated with those threats and provides infants with the ability to develop anxiety-free behavioural patterns as they mature [32]. In order to overcome the brain's innate hypersensitivity to fear, children must experience physical and emotional safety in the relationships with the adults in their lives [33].

The presence or absence of safety plays a key role in both the short term and long-term human behaviours. In the short term, individuals will engage in a series of behaviours to acquire safety, escape from threat, or both. The relative effectiveness or ineffectiveness of these behaviours are central in shaping the long-term behavioural choices that become hardwired into our brains. Escape and acquisition are the two building blocks of all behaviour. The behaviours that are effective in minimizing stress become the preferred responses to stressors for the individual. The emotional states of the person, when they are experiencing stress, become traits when behaviours consistently minimize stress [34].

In working with children and adults with significant histories of trauma, when safety is threatened later in life, the individuals appear to regress to the level of unmet need while they experienced their original trauma [35]. Understanding the lack of safety and the ages at which a person experienced trauma is a critical element in the process of recreating safety, necessitating the use of trauma screening tools. People whose subsistence needs were met in unsafe environments had significantly higher risk of developing physical and/or psychological disorders [36]. People whose needs for love and belonging were met in conditions of periodic episodes of abuse often developed psychiatric disorders [37]. People whose need for achievement, for self-esteem were met in schools and workplaces in which they were bullied are more likely to experience depression and anxiety and poorer overall emotional adjustment [38]. The need for safety is a lifelong need for all people, not just those affected by trauma. By moving safety out of the hierarchy and making it a continuous background ned, we can build systems of interactive care to help human beings grow, develop, ask questions of others and themselves, and internalize information with judgement and conviction [39]. The need for safety does not end at any point in human life; safety encompasses all points of reference for what it means to be human.

The need for safety encompasses psychological, social, physical, sexual and emotional safety. It also extends to the ways in which our neurosensory systems process incoming stimuli. People with neurosensory systems that are neuroatypical, such as people who identify as autistic, experience pain and discomfort when processing incoming stimuli such as touch, sound, sight and hearing [40].

\section{Discussion of Core Needs}

These are the first needs to be met in the first minutes and days of life and support all other needs. Subsistence needs include respiration, food, water, shelter, sleep and elimination. Each of these areas is important in their own right and are necessary to sustain our lives as human beings (Figure 2). Without these, we 


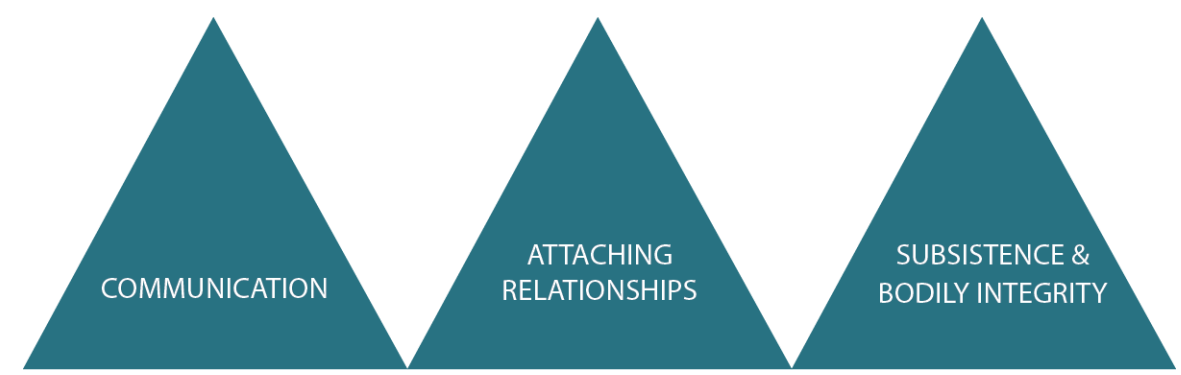

Figure 2. A visual representation of the processes of Subsistence, Attaching Relationships, and Communication which are at the core of human life.

would die within minutes or at most months depending on the need. In addition to these needs, we need to experience life free from physical pain, as the presence of pain has a significant impact on the quality of life of human beings [41].

Attaching Relationships in human beings begin in the womb [42]. When human beings are born, they are genetically programmed to attach to caregivers who will meet their basic needs necessary for survival [43]. Attaching relationships continue within several minutes or, at most, hours of birth. The eye contact between the child and parent, often mother, rocking, cooing and touch all serve to organize the brain of the infant, and reinforce the organization of the caregiver's brains [44]. These attaching relationships provide the infant and child with immediate safety at an emotional level, and also lay the foundation for psychological and emotional development [45].

Communication is presented here as a need rather than a way of meeting needs. Human beings need to communicate in order to survive. Without the social communication that enabled early hominids to function as a group, humanity would not have survived [46]. This communication system is highly complex and unlike any other known communication system. Human language production involves the vocal tract and the longs, as well as much of the human body, including the trunk, head, face, eyes and hands [47]. The evolutionary development of more specific communication using both non-verbal and verbal tools was instrumental in the development of the complex neocortex that is unique to humans.

The human brain has evolved to pursue social relationships with other brains in order to maximize the safety of the individual and the species [48]. On page 5 of an article on social biology Maurizio Meloni writes that "The brain is increasingly thought of as a tool specifically designed to create social relationships, to reach out for human relationships and company, literally made sick by loneliness and social isolation" [49]. Without communication, social behaviour would not only be meaningless; it would be impossible. While all life forms have rudimentary forms of communication through chemical means, evolutionary principles appear to favor larger, complex brains in order to cope with the demands of being in relationship with others, both at a pair-bonding level for procreation, and at a larger group and inter-group level as human civil societies formed [50].

These three needs-Subsistence, Attaching Relationships and Communica- 
tion-interact with each other to establish the foundation of human life. If Subsistence needs are not met through severe abuse or neglect, the child dies or is at risk for developing significant disabilities as she or he develops. The Adverse Childhood Experiences and numerous subsequent articles have validated this connection [51]. Likewise, failure to form Attaching Relationships results in disorders such as avoidant, resistive, and disorganized attachment and subsequent relational difficulties [52].

As infants interact with others, usually a parent, grandparent, aunt or uncle or other relatives, the behaviours which meet subsistence, attachment and communication need mold the forming brain of the infant. When a child is born, very few neural connections beyond the brain stem are in place. The behaviours the child uses to meet their needs become that child's preferred behaviours through the process of synaptogenesis, the formation of connections between neurons in the brain, or synapses [53].

The Harvard Center for the Developing Child estimates that 700 synapses, or connections between neurons, are formed every second in the developing brain of an infant [54]. Hebb's Law is commonly understood in the phrase "what fires together, wires together" [55]. When we use behaviours to attempt to meet our needs, there are neurological consequences that become part of the architecture of the brain. If we believe the interactions to have been successful, we will use the same or similar behaviours again, strengthening the neurological connections between our perception if a need, our actions to attend to that need, and the results of our actions [56].

The interactions between our environments, our genetic programming, and the choices we make are part of the matrix of our lives, which we create every moment of every day. What fires together, wires together. Understanding each person's unique matrix is more than an academic exercise, it provides the framework for understanding how our psychosocial selves are formed, and informs the process of healing when needs are unmet.

While all three of these needs are Core, Attaching Relationships appear to be the most critical to continued development. When Attaching Relationships are either unmet or partially met, the matrix supporting this person will be weak. This weakness will be seen in a variety of different ways, including limitations in processing emotions, an inability to self-regulate in times of stress and difficulty in forming relationships [57]. In the visual model, Attaching Relationships is in the middle as it provides the central balance point for growth and action in our journey towards wholeness and wellness.

When safety is lacking while human beings are learning to use social relationships, those relationships will be difficult to develop. People will have social relationships, but they often will be experienced as manipulative [58]. People with diagnoses such as Reactive Attachment Disorder, Antisocial Personality Disorder and Disinhibited Social Engagement Disorder often experienced significant levels of Adverse Childhood Experiences (ACE's) in the form of abuse 
and neglect during their early developmental stages [59]. These impairments of need fulfillment in Subsistence as well as Attaching Relationships can be seen in less than robust social relationship as the child develops and matures.

\section{Discussion of Growth Needs}

Within this model, Social Relationships and Achievement are the next two needs to be met. When the needs for Subsistence, Attaching Relationships, and Communication are fully met, the individual has a strong base upon which to begin meeting the next processes needed for continued growth. Subsistence needs, when met, provides for the physical empowerment of all human behaviours. Attaching Relationships create the ability for the individual, a developing child at this point, to form social relationships. Communication, not necessarily verbal, gives the child the ability to engage in relationships that are at first dyadic, with one other person, and then more complex as the infant becomes a child and interacts with people in social situations outside the family structure (Figure 3 ).

It is within Social Relationships that the process of attunement begins to mature beyond the dyadic relationships in the attachment process [60]. Attunement refers to a reciprocal relationship between caregiver and child in which their interactions with each other create the foundations of behavioral regulation and/or dysregulation, depending on the emotional state of the caregiver. From mother-infant relationships to more complex relationships, attunement is crucial to the development of relational skills. Without strong relational skills, people will be more likely to engage in limited social interactions, and will see achievement as something they did, as opposed to seeing how others contributed to their achievement.

The impact of interpersonal relationships on educational achievement has been well studied [61]. Less well studied is the impact of interpersonal relationships on achievement within home and community settings. The mastery and achievement of children is intimately bound up in the attaching relationships with their parents [62]. The western model of attachment being primarily a role of a mother is not at all universal and the social contexts of attachment and relationships must be broadened to include multiple social relationships supporting the child to grow, develop and succeed in their lives [63].

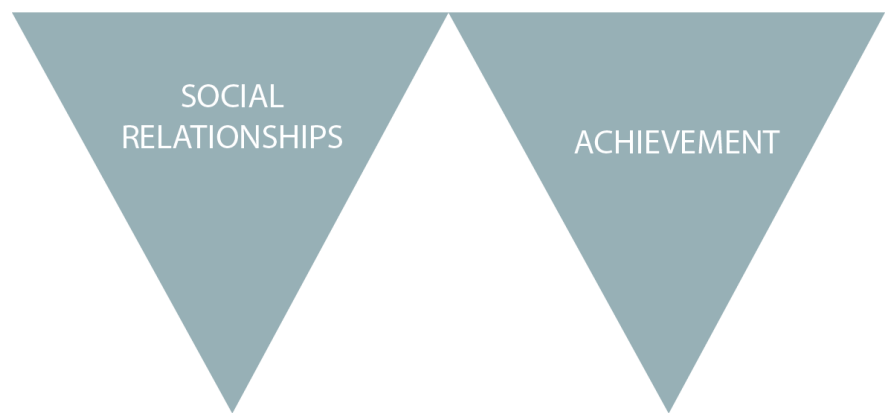

Figure 3. A visual representation of the processes needed for human beings to grow and develop higher order interactional skills needed for individual and species survival. 
Achievement is a need seen in children as they learn palmar and pincer grasp and are able to use these skills to perform tasks such as eating, attaining desired objects, etc. [64]. The pride of skill mastery is itself a motivating force in the continued growth of the individual and continues to be important throughout the lifespan [65]. It is when we are able to achieve and say "I did it" that we build a foundational platform upon which we can continue to grow and develop in our humanity. Achievement brings about self-esteem, and when Achievement is hampered by a lack of emotional or psychological safety, self-esteem suffers as well. In such cases, the individual may overcompensate by striving even harder to achieve and seek out continuous praise. Such individuals are often labeled "attention seeking" when in fact they are seeking affirmation, acceptance, and safety.

A mistake often made by parents, educators and others is to reinforcement only the outcome of the efforts made to achieve a goal, and not the effort or process that is required to achieve. Having a Growth Mindset empowers children as well as adults to have a mindset that is not fixed but rather is focused on continually growing, expanding and changing [66]. Efforts and outcomes are important, but if we only reinforce outcomes, the necessary efforts and frequent failures may become barriers instead of steppingstones. Try Another Way was a forerunner of this approach and emphasized that people with significant intellectual disabilities could achieve at high levels using the relatively simple prompt of "that was really good-try another way" [67].

\section{Observations on Stability}

When people have experienced a high degree of safety and are experiencing relative success in meeting these first five needs, they have the stability necessary from which they can continue to grow. In the visual representation in Figure 4, people have a stable life platform from which they can not only experience their lives positively now; they are also empowered to continue to mature into their individual selves and participate in the corporate life of the community. It is my observation that a significant number, and perhaps a majority of individuals receiving mental health, substance abuse, developmental disability and other structured human services are still struggling to meet these foundational needs.

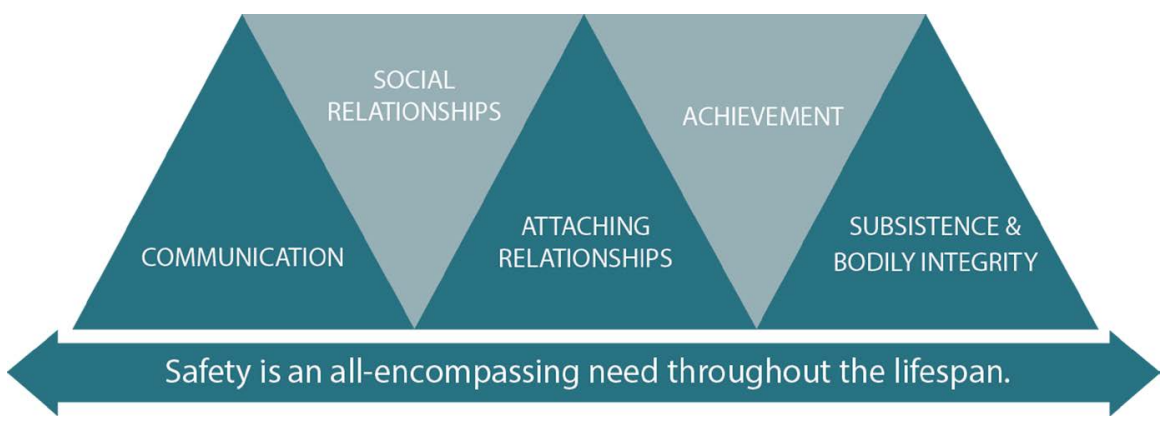

Figure 4. A visual representation of the stability provided when Safety, Core, and Growth Needs are met. 
Many of the people I have supported who have complex behavioural needs due to the complexity of their trauma histories have struggled with these processes their entire lives. Even as adults, they struggle to maintain a balance of these 5 processes and safety in their lives. Because of limited financial resources their subsistence needs are threatened on a daily basis. Some have struggled with barriers to the development of attaching relationships, while others have struggled to communicate their thoughts and feelings to others. Some of them who have diagnoses of mental health concerns have had limited achievement in their lives, and limited social relationships.

As an administrator, my task was to organize the supports needed to provide for the Safety and Subsistence needs of all the stakeholders in the organization in which I worked. I was then responsible to facilitate either the healing of Attaching Relationships or offer the opportunity for their development, to build Communication through a combination of augmentative and/or assistive communication technologies, and to offer opportunities for Achievement and Social Relationships to develop. When these processes were established and available, it was my experience that healing and health, wellness and wholeness, followed.

\section{Case Study}

James Canady was an 11-year-old boy living in a suburb of a large American city. His parents were divorced when he was seven, he had one older and one younger sibling, and attended an elementary school near his home. James had a diagnosis autism, and at age 8 he developed significant aggressive behaviors which required his mother to call the police on several different occasions, culminating in an incident in which the Department of Human Services believed James was at risk and removed him from the family home and placed him in foster care.

Using the Matrix of Needs model, the disruption in Attaching Relationships was deemed to be a significant risk, greater than the potential benefits of foster care placement. James had no threats to his Subsistence or Communication needs, and struggled with Social Relationships and Achievement in school. The Department of Human Services was presented with a proposal to use the foster care placement as a teaching opportunity for the family while the legal questions of family placement were addressed through the courts. Both the foster parents and his mother were trained in a specific behaviour support plan designed to build self-regulation for James through the achievement of specific skills modeled by the foster father and reinforced, when the opportunity arose, by a token economy using a system of grades similar to his school experience. In addition, opportunities were provided for James' mother to address her own trauma history, and to develop self-regulatory skills in order to facilitate Attaching Relationships with James.

After 8 months, James' mother had developed her own set of self-regulation skills as modeled by the foster parents and practiced in supervised visitation. 
James was able to move back into the family home, and in the ensuing two years there have been no police calls, no disruptive behaviour, and higher marks in school. The foster parents continue to provide respite services monthly, as James very much likes the foster father. The Department of Human Services, the school system, and the natural family were able to develop collaborative and cooperative relationships which continue to support the growth of James, his sister and his mother and is a reflection of Interdependent Actualization in action. The Matrix of Needs provided a common frame of reference for all the stakeholders to understand the behavioral communication taking place through James' behavioral patterns. The Family Finding Model, developed by Kevin Campbell, utilizes many of these concepts in the work of maintaining family relationships for children in an effort to provide stability and growth opportunities and has demonstrated success in achieving stability for many children in the foster care system [68].

\section{Discussion of Maturity Needs}

As we mature, our next needs are for a combination of Autonomy and Affiliative Relationships. Moving from the "I do it" process we now begin to map out our independence from our families of origin and individuate, distinguishing ourselves as individuals in our own right. Relationships now become a matter of choice as we identify others with whom we want to belong, whether it is a group at work, or an expression of faith, or an expression of creation such as music, or physical activities such as mountain climbing, etc. These are people groups we choose to identify with as opposed to being born or placed into them (Figure 5).

To be autonomous is, at minimum, self-rule that is free from both controlling interference by others and from limitations, such as inadequate understanding, that prevent meaningful choice. The autonomous individual acts freely in accordance with a self-chosen plan [69]. Autonomy is one of the drives Erikson posited, and is seen first in the young child who says, "I do it!!" and then continues to develop in skill mastery [70].

Achievement is where the sense of autonomy is first experienced, and as the child develops and matures, she can become her own person, standing for herself. When these needs are challenged by a lack of relational safety, achievement

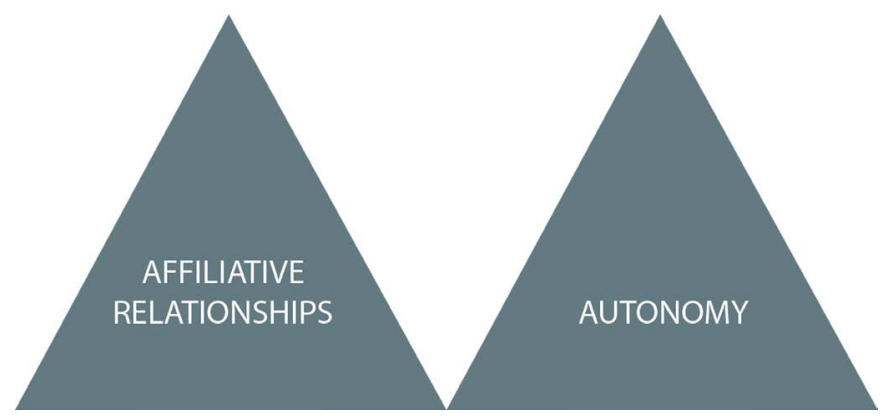

Figure 5. A visual representation of the necessary balance between being autonomous and being in self-chosen relationships meaningful to the individual. 
and autonomy are pathways to acceptance and a sense of being valued, if not loved [71]. Autonomy is built on the emotionally safe experiences of Achievement, Social Relationships, and Attachment. Without the gift of autonomy, people may use Affiliative Relationships to meet their own needs and thus become manipulative of others. At times this manipulation may appear to be positive and whole, but in the end, it is still manipulation.

The person, be they an adult or child, whose Attaching Relationships are fragile or non-existent, may use their own achievements as a way of seeking and finding validation for who they are. This person continually calls attention to their achievements and often inflates them using hyperbole to show that their work is bigger or better than that of others.

Balancing autonomy is the development of Affiliative Relationships. Built upon the safe foundation of Social Relationships, Attaching Relationships, and Communication, Affiliative Relationships in this model are characterized by choice at both individual and group levels [72]. Affiliative Relationships are where autonomous people choose to relate with each other. Attaching Relationships occur before and immediately after birth, and are core to the process of becoming human. Social Relationships develop when people engage with others within environments chosen for them by parents and families which are often based on cultural and/or religious factors. Social relationships also develop within schools where attendance is based upon geography.

Affiliative Relationships are formed in environments chosen by the individuals themselves through the acts of choosing deeper friendships beyond social relationships, which jobs to apply for and take, what colleges to apply for and attend, what coffee shops and restaurants to frequent, etc. The three layers of relationships-Attaching, Social and Affiliative-provide for the long-term needs of each individual and overall quality of life [73].

Autonomy without affiliation requires transactional relationships at best (what's in it for me?) and manipulative relationships at worst (how can I use you to achieve my aims) in relationships that have clear power differentials, and no sense of mutuality or service. Getting the balance right is crucial to the continued growth of human beings.

\section{Discussion of Fulfillment Needs}

Intimacy is, in this model, the fulfillment of all the work done thus far in becoming human. It is supported by the balance between Autonomy and Affiliative Relationships (Figure 6). To be intimate with someone is to be honest with no fear of rejection. Intimacy can include physical expressions of what is commonly called love, though intimacy includes and transcends the physical aspects of love. Intimacy requires a balance between Affiliation and Autonomy. If Affiliative relationships are a primary focus for an individual, they may become enmeshed in a dependency relationship which limits intimacy [74]. If Autonomy is the primary focus for an individual, relationships become transactional and 


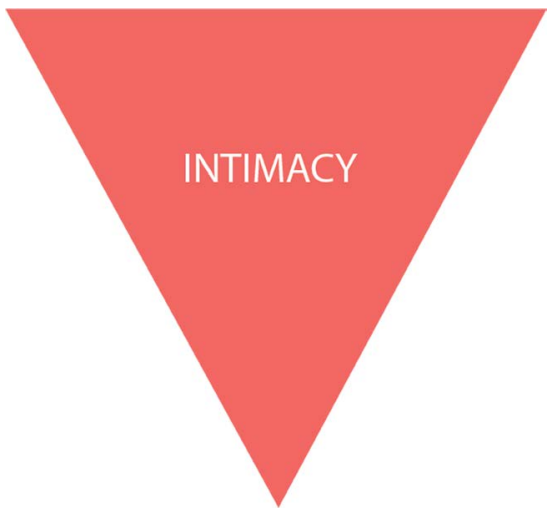

Figure 6. A visual representation of the need for intimacy within human relationships, buttressed and supported by Autonomy and Affiliative Relationships.

potentially manipulative. What I am calling intimacy here Francis Heylighen called "self-actualizing love" which "is characterized as well by respect for the other's autonomy as by ego-transcending identification of the partners' needs, as well by profound concern and care for the other's well-being as by playfulness and laughter" ([75], p44).

The relative stability of Attaching Relationships will have a strong impact on the ways in which intimacy is experienced later in life [76]. The degrees to which all other needs identified in the Matrix of Needs are or are not met will have a significant impact on the experience of intimacy. Intimacy is cradled by Autonomy and Affiliative Relationships. When we are able to stand by ourselves and stand with others, we can experience intimacy and create love, not just experience it. To be intimate with someone else is to understand them, and to be understood by them, with complete trust and without fear [77]. This understanding of intimacy crosses cultural boundaries and is felt by people in Asian as well as Western societies [78]. While the degree of intimacy varies between cultures, the need for intimacy appears to be transcultural [79].

\section{Discussion of Interdependent Actualization}

Cooperative behaviour has been thought to be a higher order phenomenon, requiring multi-cellular organisms with distinct patterns of communication. Research into the social behaviour of bacteria and other microorganisms have shown that cooperative social behaviour is ingrained into life forms at the most basic cellular level [80]. The process of quorum sensing is an example of single cell organisms cooperating with each other in order to maximize the probability that the group will survive, especially in times of limited resources [81]. Human beings have taken the biological imperative to cooperate and raised it to a higher level of possibility. It is in the basic building blocks of life that we find the urge, the need to use social behaviour in order to live. The term "interdependent actualization" is used to highlight both individual wellbeing and that of the people we interact with in our cultures (Figure 7). Wellbeing is not only an individual goal, it is also a communal goal [82]. Interdependent actualization is what empowered 


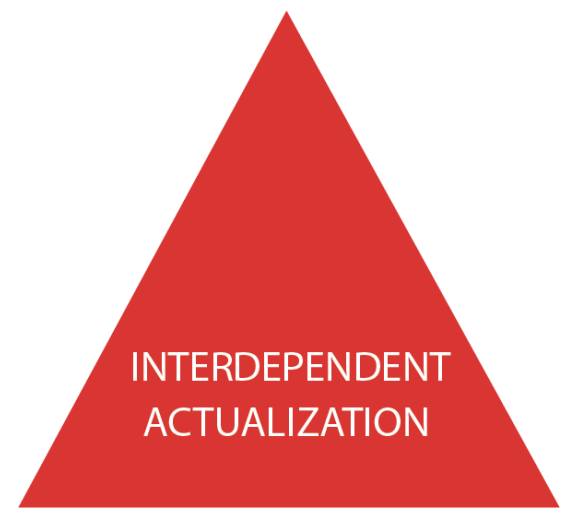

Figure 7. A visual representation of the capstone of the Matrix of Needs.

humans to flourish in harsh environments, find safety from predators, and develop civilizations. Humans built communities and civilisations using interdendence as both a starting point and a goal for their lives together.

Interdependency, the concept that we are all in this together, provides a way of understanding human actions and interactions in a way that is consistent with the Social Engagement System which postulates that human social behaviour in response to threats has evolved to empower humans to work in groups as opposed to addressing threats individually. Interdependency balances the needs of the self and the needs of the group. There is in western social thought an individualism or collectivism approach, which provides a false dichotomy. We are born as individuals and become human through social interactions. For "us" to be as actualized as possible, "I" must be as actualized as I can be. Because I live in a community I am interdependently connected with those who pick up my trash, make sure my gas and electricity flows to my house, maintain the roads, deliver goods to the stores I shop at or the internet I shop on. Maslow was on this path, and his final book, The Farther Reaches of Human Nature published after his death, is a collection of essays on a broad range of topics, including his vision of moving beyond self-actualization [83]. Maslow called the concept "self-transendence" and believed that people who had self-actualised would now use their lives in service to others [4].

Interdependency is seen in all life forms, from the simplest to the most complex, with social connections being present in microscopic forms of life [84]. Single cell organisms work together in a variety of different contexts to forage for food, disperse across a wider area, reproduce and communicate [85]. Certain species of spiders have developed complex social roles and identifiable personality traits [86]. It is not just the higher orders of mammals that practice cooperative social behaviour, it appears to be part of the structure of life on earth [87].

\section{Theory into Practice}

The second platform for stability is when all the needs, except for Interdependent Actualization, are met. In a very real sense, the person who has achieved a life with Autonomy, Affiliative Relationships and Intimacy, on top of the under- 
lying 5 needs, is Self-Actualized. In order for a person to be Interdependently Actualized, their self-hood must be actualized, or "made real."

It is harder to write about human needs using examples of people whose needs are met. The processes that make up the Matrix of Needs can be seen in more detail in stories of abuse and neglect in which the unmet needs are seen in stark relief. The effects of trauma have been well researched [88]. Understanding how abuse and neglect derail the normative developmental framework provides a guide for those interventions necessary for healing and wholeness to be experienced by the individual. This understanding also can inform the structures of health and wellness in all the places in which humans congregate outside their family settings. Identifying the points in this matrix in which traumas and insults caused harm also provides the paths through which neural plasticity and emotional resilience can be harnessed and wellness can be achieved.

While abuse and neglect have been continuously present in human history, their inclusion in the literature related to human development is relatively recent. When Maslow discussed the concept of safety, though he did not use the word "trauma" the components of traumatic interaction were identified. He wrote that: "...parental outbursts of directed to the child, calling him names, speaking to him harshly, shaking him, handling him roughly or actual physical punishment sometimes elicits total panic and terror in the child that we must assume more is involved than the physical pain alone" ([1], pp377-378).

The theoretical framework of the Matrix of Needs has been used by the author in behavioural assessments and reports in Australia and the United States since 2019. It has been especially useful in training direct support workers in residential systems, paraeducators in schools, and parents in understanding the needs of the children and adults who receive their care and/or support. The model, however, cannot be the only tool used in the mediation or remediation of unmet needs.

Edward Carr, one of the authors of the original article putting forth the idea of Positive Behaviour Support (PBS) in 1990, wrote that: Positive behaviour support (PBS) is a great and worthy idea predicated on the notion that creating a life of quality and purpose, embedded in and made possible by a supportive environment, should be the focus of our efforts as professionals. Our chief concern is not with problem behaviour, and certainly not with problem people, but rather with problem contexts ([89], p3).

Understanding the contexts in which human growth was disrupted and developing structures for healing is central to the concept of the Neurosequential Model of Therapeutics [90]. Behaviour always occurs in some kind of context, often in relationship with others, and always in relationship with the environment. Understanding those contexts and how to alter them, modify them, increase or decrease elements within the ecology requires not only a "here and now" approach; it also requires a social history identifying the ways in which trauma may have altered the development of the individual and how that altera- 
tion effects behavioural choices today. The role and importance of safety-physical, emotional, and psychological—cannot be overstated in understanding how human needs are, and sometimes are not, met. When we are able to contextualize the conversation from actualizing the self to actualizing the many communities of human interaction, the context of wellness and wholeness are extended beyond individual existence, supporting the continuation of our life together.

\section{Case Study}

Stephanie Donaldson is a 32-year-old female living in a southeastern American state. At the time of her referral, she was in a psychiatric hospital, and had been hospitalized in similar settings an average of 3 times yearly since she was 14 . Her historical record stated she was the most dangerous person in this state's mental health service system; at the time of her arrest and placement in the hospital she had injured a member of the community and a police officer who responded to the call for assistance.

Stephanie's mother was a drug addict and a prostitute, and from a very early age Stephanie was included in transactions for sex. Her case was brought to the attention of the state when she attempted to commit suicide at age 13. She had minimal attachments at this point in her life, and after approximately 25 placements between the age of 11 and 32 had not developed any stable attaching relationships. She had no income as she could not work due to her aggressive behaviours and had poor sleep patterns because of her anxiety. She had good communication skills and was able to show remarkable insight during the assessment process.

Stephanie had no social relationships outside the transient relationships in congregate settings. She had not graduated high school and when asked about things that made her proud, she answered "I got nothing to be proud of." Her diagnoses included schizophrenia, mild intellectual disabilities, and a generalized anxiety disorder.

A behavior support plan was developed after a comprehensive assessment was completed, which required 2:1 supports for 2 years, 1:1 supports for one year, and after that supports were faded. She now works independently and has drop-in supports 10 to 20 hours per month for specific assistance in financial management and counseling. The majority of the direct support staff were Nepalese Buddhists whose commitment to non-violence was instrumental in responding to Stephanie without the use of physical intervention. They were able to provide Stephanie with safety no matter how aggressive her behaviors were. During the course of the next two years, there was only 1 staff person who left for another position, providing a high degree of relational stability and safety.

After establishing safety, the plan focused primarily on building stable attaching relationships with 2 key staff who committed to work with her for a period of at least 2 years. She was able to develop social relationships and after several 
attempts was able to begin volunteering in a community service organization, which eventually led to gainful employment. Within these relational settings she was able to achieve, develop social relationships and then experience autonomy and affiliative relationships. While the cost was initially quite high with $2: 1$ staffing, over the course of 10 years there was a significant decrease in social costs to the state and a high degree of stability for Stephanie, including zero police involvements and zero psychiatric hospitalizations. By achieving stability in the first five needs, Stephanie was able to address other needs within her life, and it is reasonable to expect a full discharge from services and inclusion in the community in the near future.

In my last visit with her, she asked if her boyfriend could join us for a meal. They sat across from me in a restaurant, and she leaned against him playfully several times, and on one occasion whispered to me "we do it!" A woman with a terrible history of childhood sexual abuse and exploitation could now give her body to another person. The Matrix of Needs provided a framework for the support structures surrounding Stephanie which led to the healing she has experienced in her life.

\section{Implications for Future Research}

This article is meant to continue the examination of the interactivity of human needs, especially in light of the abuse and neglect experienced by at least one third of children, according to the Adverse Childhood Experience study. While this article has focused on the human service system, with an emphasis on developmental disability and mental health services, explorations in organizational management, forensic services, and educational programs are an example of ways in which the Matrix of Needs may be applied in other settings.

McLelland's Three Needs Theory identifies Power, Achievement and Affiliation as motivators for behavior [91]. Used predominantly in business and managerial settings, the role of unmet needs in Attaching Relationships and the resultant compensatory behaviors in Achievement, Social Relationships, Affiliative Relationships and Autonomy are topics that may shed additional light on how the relational interactions between people can result in unmet needs, and provide a roadmap for meeting those needs in the lives of individuals who struggle in many if not all of these areas.

Of particular interest to me is the Chinese model of therapy known as Zhi Mian. Like many Chinese words, there is no easy, singular translation and it has been described as "facing directly," suggesting that rather than escape from the traumatic events that might drive us to escape, or attack, we instead directly face the existential threats to our very existence Both a form of therapy and a way of living, Zhi Mian, in my understanding, can be discussed in a dyadic therapeutic relationship, but it can only be lived out in and with a group of other, likeminded people who are interdependently actualizing. I am actually quite excited about the ways Zhi Mian can expand, deepen, and strengthen our understanding 
of what it means to be human.

\section{Acknowledgements}

Vaughan Bowie was a social worker, researcher, author, teacher, but above all a great friend whose passion for healing the woundedness he encountered illuminated everything and everyone who knew him. I treasure the many hours we had over the years collaborating on articles, sharing our lives, and am forever grateful for his friendship. Vaughan had a great hunger for new approaches to understanding human needs, and it was the seeds planted in our discussions that led to this work.

Michael Privitera is a psychiatrist and colleague at the University of Rochester, and a collaborator not only in our professional writings but in life as well. Through his actions he defines what it means to be interdependently actualized, as he always seeks the healing of others while also maintaining his own sense of what it means to be human. From the proverbial bottom of my heart gratitude wells up for these two men who gave me so much and asked for nothing in return. Thank you both.

I am also indebted to Brodie Patterson, a professor, researcher and colleague from the University of Stirling in Scotland for his reading of the manuscript and his comments, and to my colleague Mitch Bayliss of Complex Behaviour Change in Castlemaine, Victoria. I am grateful for the opportunities to support individuals with complex behavioural needs through Prag Consulting in Melbourne, Australia. Shanker Pragnaratne is that rare breed of psychologist whose ethics and gentle presence compliment a rigorous and robust psychological practice. Aaryce Hayes, Gary Archibeck, Steve Fricke, Nancy Ward, Griffin Long, Sean Swanson, Rachel Long, Kat Gritter, Andy Reynolds, and Dave Gritter participated in focus groups as this work took shape, and I appreciate their input. Kaitlin Skaja developed the graphic images which greatly added to the readability of the paper, and Elliot Bowen provided insight into the biological research on the ECM and on quorum sensing. Lastly, I want to thank Celia King of Arrants-McSwain Consulting for her rigorous intellect, and the encouragement to push forward with this work. Without her energy and drive, I would have kept researching and writing and this work might never have left my computer.

\section{Human Subjects and Research}

No studies involving human beings or animals were conducted in the writing of this article. Case studies have been anonymized.

\section{Conflicts of Interest}

The author declares no conflicts of interest regarding the publication of this paper.

\section{References}

[1] Maslow, A.H. (1943) A Theory of Human Motivation. Psychological Review, 50, 
370-396. https://doi.org/10.1037/h0054346

[2] Kenrick, D.T., Griskevicius, V., Neuberg, S.L. and Schaller, M. (2010) Renovating the Pyramid of Needs: Contemporary Extensions Built on Ancient Foundations. Perspectives in Contemporary Psychology, 5, 292-314. https://doi.org/10.1177/1745691610369469

[3] Max-Neef, M. (1992) Development and Human Needs. In: Ekins, P. and Max-Neef, M., Eds., Real Life Economics. Understanding Wealth Creation, Routledge, London, 97-213.

[4] Koltko-Rivera, M.E. (2006) Rediscovering the Later Version of Maslow's Hierarchy of Needs: Self-Transcendence and Opportunities for Theory, Research, and Unification. Review of General Psychology, 10, 302-317. https://doi.org/10.1037/1089-2680.10.4.302

[5] Huitt, W. (2007) Maslow's Hierarchy of Needs. Educational Psychology Interactive. Valdosta State University, Valdosta.

http://www.edpsycinteractive.org/topics/conation/maslow.html

[6] Sherin, J.E. and Nemeroff, C.B. (2011) Post-Traumatic Stress Disorder: The Neurobiological Impact of Psychological Trauma. Dialogues in Clinical Neuroscience, 13, 263-278. https://doi.org/10.31887/dcns.2011.13.2/jsherin

[7] Zheng, Z., Gu, S., Lei, Y., Lu, S., Wang, W., Li, Y. and Wang, F. (2016) Safety Needs Mediate Stressful Events Induced Mental Disorders. Neural Plasticity, 2016, Article ID: 8058093. https://doi.org/10.1155/2016/8058093

[8] Kaiser, D.H., McAdams, C.R. and Foster, V.A. (2012) Disequilibrium and Development: The Family Counseling Internship Experience. The Family Journal, 20, 225-232. https://doi.org/10.1177\%2F1066480712448787

[9] Bonnans, C., Chou, J. and Werb, Z. (2014) Remodeling the Extra-Cellular Matrix in Development and Disease. Nature Reviews Molecular Cellular Biology, 15, 786-801. https://doi.org/10.1038/nrm3904

[10] Hussey, G.S., Dziki, J.L. and Badylak, S.F. (2018) Extra-Cellular Matrix-Based Materials for Regenerative Medicine. Nature Reviews Materials, 3, 159-173. https://doi.org/10.1038/s41578-018-0023-x

[11] Alberts, B., Johnson, A., Lewis, J., et al. (2002) Molecular Biology of the Cell. 4th Edition. Garland Science, New York, Chapter 19, Cell Junctions, Cell Adhesion, and the Extracellular Matrix. https://www.ncbi.nlm.nih.gov/books/NBK21047/

[12] Renner, L. (2020) What Lies Inside [Film]. Birdshine Films, Pendleton, IN.

[13] Houser, N.O. (2012) Negotiating Dissonance and Safety for the Common Good: Social Education in the Elementary Classroom. Theory and Research in Social Education, 24, 294-312. https://doi.org/10.1080/00933104.1996.10505780

[14] Kim, S., Lee, H. and Connerton, T.P. (2020) How Psychological Safety Affects Team Performance: Mediating Role of Efficacy and Learning Behavior. Frontiers in Psychology, 11, Article No. 1581. https://doi.org/10.3389/fpsyg.2020.01581 https://www.frontiersin.org/article/10.3389/fpsyg.2020.01581

[15] Porges, S.W. (2001) The Polyvagal Theory: Phylogenetic Substrates of a Social Nervous System. International Journal of Psychophysiology, 42, 123-146. https://doi.org/10.1016/S0167-8760(01)00162-3

[16] Richerson, P.J. and Boyd, R. (2005) Not by Genes Alone: How Culture Transformed Human Evolution. University of Chicago Press, Chicago. https://doi.org/10.7208/chicago/9780226712130.001.0001

[17] Kellerman, N.P. (2011) Epigenetic Transmission of Holocaust Trauma: Can Night- 
mares Be Inherited? Israeli Journal of Psychiatry and Related Sciences, 50, 33-39.

[18] Kubota, T., Miyake, K. and Hirasawa, T. (2012) Epigenetic Understanding of Gene-Environment Interactions in Psychiatric Disorders: A New Concept in Clinical Epigenetics. Clinical Epigenetics, 4, Article No. 2. https://doi.org/10.1186/1868-7083-4-1

[19] Melé, D. and Cantón, C.G. (2014) Relational Dimensions of the Human Being. In: Human Foundations of Management, IESE Business Collection, Palgrave Macmillan, London, 178-203. https://doi.org/10.1057/9781137462619 10

[20] Brown, B. (2012) Daring Greatly: How the Courage to Be Vulnerable Transforms the Way We Live, Love, Parent and Lead. Penguin Random House, New York.

[21] Cambridge Dictionary (2020) Meaning of the Word “Actualize". https://dictionary.cambridge.org/us/dictionary/english/actualize

[22] Geisler Fay, C.M., Kubiak, T., Siewert, K. and Weber, H. (2013) Cardiac Vagal Tone Is Associated with Social Engagement and Self-Regulation. Biological Psychology, 93, 279-286. https://doi.org/10.1016/j.biopsycho.2013.02.013

[23] Venables, R.W. (2010) The Clearings and the Woods: The Haudenosaunee (Iroquois) Landscape-Gendered and Balanced. In: Baugher, S.B. and Spencer-Wood, S.M., Eds., Archaeology and Preservation of Gendered Landscapes, Springer, New York, 21-55. https://doi.org/10.1007/978-1-4419-1501-6 2

[24] Salkovskis, P.M., Clark, D.M.,, Hackmann, A., Wells, A. and Gelder, M.G. (1999) An Experimental Investigation of the Role of Safety-Seeking Behaviours in the Maintenance of Panic Disorder with Agoraphobia. Behaviour Research and Therapy, 37, 559-574. https://doi.org/10.1016/S0005-7967(98)00153-3

[25] Thwaites, R. and Freeston, M.H. (2005) Safety-Seeking Behaviours: Fact or Function? How Can We Clinically Differentiate between Safety Behaviours and Adaptive Coping Strategies across Anxiety Disorders? Behavioural and Cognitive Psychotherapy, 2005, 177-188. https://doi.org/10.1017/S1352465804001985

[26] Low, P. (2017) Overview of the Autonomic Nervous System. https://www.merckmanuals.com/home/brain,-spinal-cord,-and-nerve-disorders/aut onomic-nervous-system-disorders/overview-of-the-autonomic-nervous-system

[27] Balezeau, F., Wilson, B., Gallardo, G., Dick, F., Hopkins, W., Anwander, A., Friederici, A.D., Griffiths, T.D. and Petkov, C.I. (2020) Primate Auditory Prototype in the Evolution of the Arcuate Fasciculus. Nature Neuroscience, 23, 611-614.

[28] Committee on Child Maltreatment Research, Policy, and Practice for the Next Decade: Phase II; Board on Children, Youth, and Families; Committee on Law and Justice; Institute of Medicine; National Research Council (2014) 4. Consequences of Child Abuse and Neglect. In: Petersen, A.C., Joseph, J. and Feit, M., Eds., New Directions in Child Abuse and Neglect Research, National Academies Press (US), Washington DC, 111-174. https://www.ncbi.nlm.nih.gov/books/NBK195987/

[29] Porges, S.W. (1995) Orienting in a Defensive World: Mammalian Modifications of Our Evolutionary Heritage. Psychophysiology, 32, 301-318. https://doi.org/10.1111/j.1469-8986.1995.tb01213.x

[30] Virtcka, P. and Vuillermier, P. (2012) Neuroscience of Human Social Interactions and Adult Attachment Style. Frontiers in Human Neuroscience, 6, Article No. 212. https://doi.org/10.3389/fnhum.2012.00212

[31] Graham, A.M., Buss, C., Rasmussen, J.M., Rudolph, M.D., Demeter, D.V., Gilmore, J.H., et al. (2016) Implications for Newborn Amygdala Connectivity for Fear and Cognitive Development at 6 Months-of-Age, Developmental Cognitive Neuroscience, 18, 12-25. https://doi.org/10.1016/j.dcn.2015.09.006 
[32] Cozolino, L. (2014) The Neuroscience of Human Relationships: Attachment and the Developing Social Brain. WW Norton \& Company, New York.

[33] Perry, B.D. (2004) Understanding Traumatized and Maltreated Children: The Core Concepts. Video Training Series 1, The Child Trauma Academy, Houston.

[34] Perry, B.D., Pollard, R.A., Blaicley, T.L., Baker, W.L. and Vigalante, D. (1995) Childhood Trauma, the Neurobiology of Adaptation and "Use Dependent" Development of the Brain: How "States" Become "Traits". Infant Mental Health Journal, 16, 271-291.

https://doi.org/10.1002/1097-0355(199524)16:4\%3C271::AID-IMHJ2280160404\%3E 3.0.CO;2-B

[35] Lokko, H.N. and Stern, T.A. (2015) Regression: Diagnosis, Evaluation and Management. The Primary Care Companion for CNS Disorders, 17, 115.

https://doi.org/10.4088/PCC.14f01761

[36] Anda, R.F., Felitti, F.J., Bremner, M.D., Walker, J.D., Whitfield, C., Perry, B.D., Dube, S.R. and Giles, W.H. (2006) The Enduring Effects of Abuse and Related Adverse Experiences in Childhood. European Archives of Psychiatry and Clinical Neuroscience, 256, 174-186. https://doi.org/10.1007/s00406-005-0624-4

[37] van der Kolk, B.A. (2014) The Body Keeps the Score: Brain, Mind and Body in the Healing of Trauma. Penguin Books, New York.

[38] Gladstone, G.L., Parker, G.B. and Malhi, G.S. (2006) Do Bullied Children Become Anxious and Depressed Adults? A Cross-Sectional Investigation of the Correlates of Bullying and Anxious Depression. The Journal of Nervous and Mental Disease, 194, 201-208. https://doi.org/10.1097/01.nmd.0000202491.99719.c3

[39] Quiros, L., Kay, L. and Montijo, A.M. (2012) Creating Emotional Safety in the Classroom and in the Field. Reflections, 18, 42-47.

[40] Clark, C. (2015) Autism Spectrum Disorder and Amplified Pain. Case Reports in Psychiatry, 2015, Article ID: 930874. https://doi.org/10.1155/2015/930874

[41] Oliveira, C.C. (2016) Understanding Pain and Human Suffering. Revista Bioética, 24, 225-234. https://doi.org/10.1371/journal.pone.0013199

[42] Castiello, U., Becchio, C., Zola, S., Nelini, C., Sartori, L., Blason, L., D’Ottavio, G., Bulgheroni, M. and Gallese, V. (2010) Wired to Be Social: The Ontogeny of Human Interaction. PLoS ONE, 5, e13199. https://doi.org/10.1371/journal.pone.0013199

[43] Cassidy, J., Jones, J.D. and Shaver, P.R. (2013) Contributions of Attachment Theory and Research: A Framework for Future Research, Translation, and Policy. Development and Psychopathology, 25, 1415-1434. https://doi.org/10.1017/S0954579413000692

[44] Leong, V., Byrne, E., Clackson, K., Georgieva, S., Lam, S. and Wass, S. (2017) Speaker Gaze Increases Information Coupling between Infant and Adult Brains. Proceedings of the National Academy of Sciences of the United States of America, 114, 13290-13295. https://doi.org/10.1073/pnas.1702493114

[45] Hong, Y.R. and Park, J.S. (2012) Impact of Attachment, Temperament and Parenting on Human Development. Korean Journal of Pediatrics, 55, 449-454. https://doi.org/10.3345/kjp.2012.55.12.449

[46] Fay, N., Garrod, S., Roberts, L. and Swoboda, N. (2010) The Interactive Evolution of Human Communication Systems. Cognitive Science, 34, 351-386. https://doi.org/10.1111/j.1551-6709.2009.01090.x

[47] Levinson, S.C. and Holler, J. (2014) The Origin of Human Multi-Modal Communication. Philosophical Transactions of the Royal Society, 369, Article ID: 20130302. 
https://doi.org/10.1098/rstb.2013.0302

[48] Muthukrishna, M., Doebeli, M., Chudek, M. and Henrich, J. (2018) The Cultural Brain Hypothesis: How Culture Drives Brain Expansion, Sociality, and Life History. PLoS Computational Biology, 14, e1006504. https://doi.org/10.1371/journal.pcbi.1006504

[49] Meloni, M. (2014) The Social Brain Meets the Reactive Genome: Neuroscience, Epigenetics and the New Social Biology. Frontiers in Neuroscience, 8, Article No. 309. https://doi.org/10.3389/fnhum.2014.00309

[50] Dunbar, R.I.M. and Schultz, S. (2007) Evolution in the Social Brain. Science, 317, 1344-1347. https://doi.org/10.1126/science.1145463

[51] Kerker, B.D., Zhang, J., Nadeem, E., Stein, R.K., Hurlburt, M.S., Heneghan, A., Landsverk, J. and Howritz, S.M. (2015) Adverse Childhood Experiences and Mental Health, Chronic Medical Conditions, Ad Development in Young Children. Academic Pediatrics, 15, 510-517. https://doi.org/10.1016/j.acap.2015.05.005

[52] Benoit, D. (2004) Infant-Parent Attachment: Definition, Types, Antecedents, Measurement and Outcome. Paediatrics \& Child Health, 9, 541-545.

https://doi.org/10.1093/pch/9.8.541

[53] Petzoldt, A.G. and Sigrist, S.J. (2014) Synaptogenesis. Current Biology, 24, R1076-R1080. https://doi.org/10.1016/j.cub.2014.10.024

[54] Shonkoff, J.P. (2013) Driving Science-Based Innovation to Strengthen the Foundation of Lifelong Learning, Behaviour and Health. NCSL Early Learning Fellows Webinar. http://www.ncsl.org/documents/cyf/Shonkoff Webinar.pdf

[55] Keysers, C. and Gazzola, V. (2014) Hebbian Learning and Predictive Mirror Neurons for Actions, Sensations and Emotions. Philosophical Transactions of the Royal Society of London, Series B: Biological Sciences, 369, Article ID: 20130175. https://doi.org/10.1098/rstb.2013.0175

[56] Rasmussen, D., Voelker, A. and Eliasmith, C. (2017) A Neural Model of Hierarchical Reinforcement Learning. PLoS ONE, 12, e0180234. https://doi.org/10.1371/journal.pone.0180234

[57] Rees, C. (2007) Childhood Attachment. British Journal of General Practice, 57, 920-922.

[58] Brewer, G. and Abell, L. (2017) Machiavellianism, Relationship Satisfaction and Romantic Relationship Quality. Europe's Journal of Psychiatry, 13, 491-502. https://doi.org/10.5964/ejop.v13i3.1217

[59] Lehman, S., Brevik, K., Heiervang, E.R., Havik, T. and Havik, O.E. (2016) Reactive Attachment Disorder and Disinhibited Social Engagement Disorder in School-Aged Foster Children-A Confirmatory Approach to Dimensional Measures. Journal of Abnormal Child Psychology, 44, 445-457.

https://doi.org/10.1007/s10802-015-0045-4

[60] Siegel, D.J. (2007) The Mindful Brain: Reflection and Attunement in the Cultivation of Well-Being. WW Norton \& Company, New York.

[61] Martin, A.J. and Dowson, M. (2009) Interpersonal Relationships, Motivation, Engagement and Achievement: Yields for Theory, Current Issues and Educational Practice. Review of Educational Research, 79, 327-365.

https://doi.org/10.3102\%2F0034654308325583

[62] Pomerantz, E.M., Grolnick, W.S. and Price, C.E. (2005) The Role of Parents in How Children Approach Achievement: A Dynamic Process Perspective. In: Elliot, A.J. and Dweck, C.S., Eds., Handbook of Competence and Motivation, Guilford Publi- 
cations, New York, NY, 229-278.

[63] Keller, H. (2016) Attachment: A Pancultural Need but a Cultural Construct. Current Opinion in Psychology, 8, 59-63. https://doi.org/10.1016/j.copsyc.2015.10.002

[64] Dosman, C.F., Andrews, D. and Goulden, K.J. (2012) Evidence-Based Milestones as a Framework for Developmental Surveillance. Pediatrics \& Child Health, 17, 561-568. https://doi.org/10.1093/pch/17.10.561

[65] Williams, L.A. and De Steno, D. (2008) Pride and Perseverance: The Motivational Role of Pride. Journal of Personality and Social Psychology, 94, 1007-1017. https://doi.apa.org/doi/10.1037/0022-3514.94.6.1007

[66] Dweck, C.S. (2006) Mindset: The New Psychology of Success. Ballantine Books, New York.

[67] Gold, M. (1973) Try Another Way-Video Training Program. Minnesota Council on Developmental Disabilities, St. Paul, MN.

https://mn.gov/mnddc/extra/marc-gold1.html

[68] Garwood, M.M. and Williams, S.C. (2015) Differing Effects of Family Finding Service on Permanency and Family Connectedness for Children New to Versus Lingering in the Foster Care System. Journal of Public Child Welfare, 9, 115-133. https://doi.org/10.1080/15548732.2015.1008619

[69] Varelius, J. (2006) The Value of Autonomy in Medical Ethics. Medicine, Health Care and Philosophy, 9, 377-388. https://doi.org/10.1007/s11019-006-9000-z

[70] Graves, S.B. and Larkin, E. (2006) Lessons from Erikson: A Look at Autonomy across the Lifespan. Journal of Intergenerational Relationships, 4, 61-71. https://doi.org/10.1300/J194v04n02 05

[71] Nietzel, M.T. and Harris, M.J. (1990) Relationship of Dependency and Achievement/Autonomy to Depression. Clinical Psychology Review, 10, 279-297. https://doi.org/10.1016/0272-7358(90)90063-G

[72] Zijlstra, T.W., de Vries, H. and Sterck, E.H.M. (2021) Emotional Bookkeeping and Differentiated Affiliative Relationships: Exploring the Role of Dynamics and Speed in Updating Relationship Quality in the EMO-Model. PLoS ONE, 16, e0249519.

[73] Sutcliffe, A., Dunbar, R., Binder, J. and Arrow, H. (2012) Relationships and the Social Brain: Integrating Psychological and Evolutionary Perspectives. British Journal of Psychology, 103, 149-168. https://doi.org/10.1111/j.2044-8295.2011.02061.x

[74] Layder, D. (2009) Intimacy and Power: The Dynamics of Personal Relationships in Modern Society. Palgrave MacMillan, London.

[75] Heylighen, F. (1992) A Cognitive-Systemic Reconstruction of Maslow's Theory of Self-Actualization. Behavioural Science, 37, 39-58. https://doi.org/10.1002/bs.3830370105

[76] Grabill, C.M. and Kerns, K.A. (2005) Attachment Style and Intimacy in Friendship. Personal Relationships, 7, 363-378. https://doi.org/10.1111/j.1475-6811.2000.tb00022.x

[77] Erber, R. and Erber, M.W. (2018) Intimate Relationships: Issues, Theories, and Research. Routledge, New York. https://doi.org/10.4324/9781315110103

[78] Marshall, T. (2010) Love at the Cultural Crossroads: Intimacy and Commitment in Chinese Canadian Relationships. Personal Relationships, 17, 391-411. https://doi.org/10.1111/j.1475-6811.2010.01280.x

[79] You, H.S. and Malley-Morrison, K. (2010) Young Adult Attachment Styles and Intimate Relationships with Close Friends: A Cross Cultural Study between Koreans and Caucasian Americans. Journal of Cross Cultural Psychology, 31, 528-534. 
https://doi.org/10.1177\%2F0022022100031004006

[80] Young, S.N. (2008) The Neurobiology of Human Social Behaviour: An Important but Neglected Topic. Revolutions in Psychiatric Neuroscience, 33, 391-392.

[81] Miller, M.B. and Bassler, B.L. (2001) Quorum Sensing in Bacteria. Annual Review of Microbiology, 55, 165-199. https://doi.org/10.1146/annurev.micro.55.1.165

[82] Le, B.M., Impett, E.A., Lemay, E.P., Muise, A. and Tskhay, K.O. (2018) Communal Motivation and Well-Being in Interpersonal Relationships: An Integrative Review and Meta-Analysis. Psychological Bulletin, 144, 1-25. https://doi.apa.org/doi/10.1037/bul0000133

[83] Maslow, A.H. (1971) The Farther Reaches of Human Nature. Viking Press, New York.

[84] West, S.A., Diggle, S.P., Buckling, A., Gardner, A. and Griffin, A.S. (2007) The Social Lives of Microbes. Annual Review of Ecology, Evolution, and Systematics, 38, 53-77. https://doi.org/10.1146/annurev.ecolsys.38.091206.095740

[85] Crespi, B.J. (2001) The Evolution of Social Behavior in Microorganisms. Trends in Ecology \& Evolution, 16, 178-183. https://doi.org/10.1016/S0169-5347(01)02115-2

[86] Laskowski, K.L. and Pruitt, J.N. (2014) Evidence of Social Niche Construction: Persistent and Repeated Social Interactions Generate Stronger Personalities in a Social Spider. Proceedings of the Royal Society B: Biological Sciences, 281, Article No. 30133166. https://doi.org/10.1098/rspb.2013.3166

[87] Novak, M.A. (2005) Five Rules for the Evolution of Cooperation. Science, 314, 1560-1563. https://doi.org/10.1126/science.1133755

[88] Oral, R., Ramirez, M., Coohey, C., Nakada, S., Walz, A., Kuntz, A., Benoit, J. and Peek-Asa, C. (2015) Adverse Childhood Experiences and Trauma Informed Care: the Future of Health Care. Pediatric Research, 79, 227-233.

https://doi.org/10.1038/pr.2015.197

[89] Carr, E.G. (2007) The Expanding Vision of Positive Behavior Support: Research Perspectives on Happiness, Helpfulness, Hopefulness. Journal of Positive Behavior Interventions, 9, 3-14. https://doi.org/10.1177\%2F10983007070090010201

[90] Barfield, S., Dobson, C., Gaskill, R. and Perry, B.D. (2014) Neurosequential model of Therapeutic in a Therapeutic Preschool: Implications for Work with Children with Complex Neuropsychiatric Problems. The Advanced Generalist. Social Work Research Journal, 1, 64-80.

[91] Anderson, J.A. (2018) Manager's Motivation Profiles: Measurement and Application. Sage Open, 8, 1-9. https://doi.org/10.1177\%2F2158244018771732 